\title{
Synthesis of Three-Dimensional Hierarchical Urchinlike Tungsten Trioxide Microspheres for High-Performance Supercapacitor Electrode
}

\author{
Xu He ${ }^{1}$, Junning Wan ${ }^{1}$, Dong He ${ }^{1, *}$,, Xiaotian Yang ${ }^{2}$, Hui Suo ${ }^{1}$ and Chun Zhao ${ }^{1}$ \\ 1 State Key Laboratory of Integrated Optoelectronics, College of Electronic Science and Engineering, Jilin \\ University, Changchun 130118, China; hexv1116@163.com (X.H.); wanjn18@mails.jlu.edu.cn (J.W.); \\ suohui@jlu.edu.cn (H.S.); zchun@jlu.edu.cn (C.Z.) \\ 2 Jilin Provincial Key Laboratory of Architectural Electricity and Comprehensive Energy Saving, \\ Changchun 130118, China; hangxt@163.com \\ * Correspondence: hedong@jlu.edu.cn
}

Received: 23 August 2019; Accepted: 17 September 2019; Published: 19 September 2019

\begin{abstract}
In this work, hierarchical three-dimensional (3D) urchinlike $\mathrm{WO}_{3}$ microspheres with a self-assembled nanorod core, and a connected and quasiconnected nanothorn network shell were synthesized with the hydrothermal method. For the surface or near-surface regions of pseudocapacitive materials that are involved in the Faradaic reaction, the urchinlike $\mathrm{WO}_{3}$ special microstructure provided more effective charge-storage area, exhibiting a high specific capacitance of $488.78 \mathrm{~F} \mathrm{~g}^{-1}$, low average equivalent-series resistance of $0.966 \Omega \mathrm{cm}^{-2}$, and excellent cycling stability ( $84.75 \%$ of its initial value after the 10,000 cycles). This performance indicates the urchinlike $\mathrm{WO}_{3}$ microspheres are promising electrode materials for high-performance supercapacitors.
\end{abstract}

Keywords: tungsten trioxide; three-dimensional; energy storage and conversion; supercapacitor

\section{Introduction}

Due to their characteristics of high-power density, long cycling stability, high conversion efficiency, and easy maintenance, supercapacitors have become a promising candidate for renewable-energy conversion and storage devices, especially for photovoltaic- and wind-power generation and transition [1,2]. However, the relatively low specific capacitance and relatively high average equivalent-series resistance caused by the preparation technique limit further applications in the renewable-energy field [3]. It is well known that pseudocapacitive materials obtain higher specific capacitance than double-layer capacitive materials due to their unique energy-storage method, which depends on the Faraday reactions on the surface or near-surface regions of the microstructure of the materials to charge and discharge. Thus, methods to control the structures of pseudocapacitive materials (i.e., morphology and crystal structure) should be found to improve charge and ion-transfer efficiency, and to enhance the utilization of the pseudoactive material. Designing and synthesizing high-performance transition metal-oxide electrode materials with various nano-/micromorphologies and spatial structures can significantly improve the electrochemical performance of supercapacitors $[4,5]$. For example, Gao et al. [6] designed hierarchical hollow $\mathrm{MnO}_{2}$ nanostructures by using polyaniline spheres as reactive templates that revealed a specific capacitance of $308 \mathrm{~F} \mathrm{~g}^{-1}$. Xiao et al. designed rough $\mathrm{NiCo}_{2} \mathrm{~S}_{4}$ nanorod arrays with open-top electrode materials that exhibited a specific capacitance of $497 \mathrm{~F} \mathrm{~g}^{-1}$ [7]. Zhang et al. synthesized and prepared $\mathrm{Zn}-\mathrm{Co}-\mathrm{S}$ rhombic dodecahedral-cage electrode materials that demonstrated a specific capacitance of $1266 \mathrm{~F} \mathrm{~g}^{-1}$ [8]. In recent years, tungsten oxides have received extensive attention from scholars as transition metal oxides. For example, Yao et al. [9] reported that nanowires assembled sub-WO3 urchinlike nanostructures for a superior room-temperature alcohol 
sensor. Li et al. [10] introduced a type of excellent catalytic tungsten oxide nanostructure. They have also been researched as supercapacitor electrodes because of their characteristics of multiple oxidation states, high electronic conductivity, and fast ion insertion/deinsertion. $\mathrm{Xu}$ et al. [11] prepared nanofiber self-assembled mesoscopic $\mathrm{WO}_{3}$ microspheres with the hydrothermal method, which revealed a specific capacitance of $797.05 \mathrm{~F} \mathrm{~g}^{-1}$. Yoon et al. [12] synthesized ordered mesoporous tungsten oxide electrode materials with the template method that exhibited a specific capacitance of $199 \mathrm{~F} \mathrm{~g}^{-1}$. Though remarkable progress has been made, transition metal-oxide electrode materials are still limited by the relatively short cyclic life caused by expansion/contraction during the charging and discharging process [13].

In this study, hierarchical 3D urchinlike $\mathrm{WO}_{3}$ microspheres with a self-assembled nanorod core and a connected- and quasiconnected-nanothorn network shell were synthesized with the hydrothermal method. The unique microstructures could minimize structural damage during the charging and discharging process, and provide numerous active sites for Faradaic reactions, which increases the utilization of pseudocapacitive materials. Different from other $\mathrm{WO}_{3}$ materials, urchinlike $\mathrm{WO}_{3}$ is composed of numerous $\mathrm{WO}_{3}$ nanorods that can still show excellent performance even when using the traditional wafer electrode fabrication process. Hence, the prepared $\mathrm{WO}_{3}$ electrode exhibited high specific capacitance, low average equivalent-series resistance, and excellent stability, demonstrating great potential in practical applications.

\section{Materials and Methods}

All reagents used in the experiment were purchased from Sinopharm Chemical Reagent Co. Ltd. The 3D urchinlike $\mathrm{WO}_{3}$ microspheres were hydrothermally prepared following an annealing process. In brief, $15 \mathrm{mmol}$ of $\mathrm{Na}_{2} \mathrm{WO}_{3} \cdot 2 \mathrm{H}_{2} \mathrm{O}$ was dissolved in $100 \mathrm{~mL}$ deionized water (DI) and stirred for $20 \mathrm{~min}$ at room temperature $\left(25^{\circ} \mathrm{C}\right)$. Then, $9 \mathrm{~mL}$ of a $3 \mathrm{M} \mathrm{HCl}$ solution was dropwise added into the $\mathrm{Na}_{2} \mathrm{WO}_{3} \cdot 2 \mathrm{H}_{2} \mathrm{O}$ solution under magnetic stirring. Subsequently, $42 \mathrm{mmol}_{2} \mathrm{C}_{2} \mathrm{O}_{4}$ was added in to the above solution with $5 \mathrm{~min}$ magnetic stirring. Then, the mixture solution was diluted to $250 \mathrm{~mL}$. Next, $50 \mathrm{~mL}$ of the previous solution was transferred to a $100 \mathrm{~mL}$ beaker, and $2.5 \mathrm{~g}$ of $\left(\mathrm{NH}_{4}\right)_{2} \mathrm{SO}_{4}$ was added into the solution and stirred for $2 \mathrm{~h}$ at $60^{\circ} \mathrm{C}$. Subsequently, $30 \mathrm{~mL}$ of the precursor was transferred into a Teflon-lined stainless autoclave, sealed, and maintained at $180^{\circ} \mathrm{C}$ for $16 \mathrm{~h}$. After the hydrothermal treatment, the blue-green solid product was centrifuged and rinsed thoroughly with DI and ethanol. Finally, the 3D urchinlike $\mathrm{WO}_{3}$ microsphere sample was obtained by annealing at $450{ }^{\circ} \mathrm{C}$ for $1 \mathrm{~h}$.

The general and detailed morphologies and nanostructures were examined by field-emission scanning electron microscope (FESEM; JEOL JEM 6700F, JEOL, Ltd, Tokyo, Japan). The composition and phase of the samples were evaluated by X-ray diffraction (XRD, Shimadzhu 6000, Shimadzu Co., Ltd, Kyoto, Japan) and X-ray photoelectron spectroscopy (XPS, ESCALAB 250, ThermoFisher Scientific Co., Ltd, Massachusetts, USA).

The working electrode was prepared by mixing as-prepared $\mathrm{WO}_{3}$ powder with polytetrafluoroethylene and acetylene black at a weight ratio of 8:1:1, and then the slurry was pasted onto the $1.0 \times 1.5 \mathrm{~cm}^{2}$ stainless-steel mesh (the pasted zone was $1.0 \times 1.0 \mathrm{~cm}^{2}$ ). The resulting paste was pressed under $10 \mathrm{MPa}$ and dried at $40{ }^{\circ} \mathrm{C}$ overnight. Each WO3 electrode contained about $10 \mathrm{mg}$ of electroactive material. The prepared sample was tested in a 3-electrode cell on CHI-760E electrochemical station by cycle voltammetry (CV) and galvanostatic charge-discharge (GCD) measurements.

\section{Results and Discussion}

The XRD patterns of the 3D urchinlike $\mathrm{WO}_{3}$ sample are presented in Figure 1a. All the sharp peaks could be well-indexed to the monoclinic $\mathrm{WO}_{3}$ (JCPDS No.071-2141), and no other diffraction peaks could be observed, revealing the high purity and high crystallinity of the sample. In the XRD patterns, some characteristic peaks were found at $2 \theta \approx 23.1^{\circ}, 23.58^{\circ}, 24.39^{\circ}, 26.6^{\circ}, 28.95^{\circ}, 33.27^{\circ}, 33.59^{\circ}$, $34.19^{\circ}, 35.67^{\circ}, 41.45^{\circ}, 41.91^{\circ}, 44.29^{\circ}, 44.92^{\circ}, 45.4^{\circ}, 47.26^{\circ}, 48.24^{\circ}, 49.96^{\circ}, 50.34^{\circ}, 53.48^{\circ}, 54.16^{\circ}, 54.78^{\circ}$, 
$55.8^{\circ}, 57.64^{\circ}, 58.19^{\circ}, 60.98^{\circ}, 61.89^{\circ}, 62.27^{\circ}, 66.66^{\circ}, 67.28^{\circ}, 69.85^{\circ}, 71.36^{\circ}, 71.99^{\circ}, 73.03^{\circ}, 76.84^{\circ}$, and $78.61^{\circ}$, which could unambiguously be indexed to the (002), (020), (200), (120), (112), (022), (-202), (202), (122), (-222), (222), (320), (132), (-312), (004), (040), (140), (-114), (024), (042), (240), (142), (-332), (332), (043), (105), (340), (234), (324), (044), (144), (035), (-441), (424), and (600) planes of the monoclinic $\mathrm{WO}_{3}$. Figure $1 \mathrm{~b}$ and $\mathrm{c}$ shows the SEM images of the surface morphologies of the urchinlike $\mathrm{WO}_{3}$ sample from low to high magnification. In Figure $1 \mathrm{~b}$, the $\mathrm{WO}_{3}$ microspheres with diameters of 3-6 $\mu \mathrm{m}$ were like sea urchins, exhibiting spherical and thorniness characteristics.
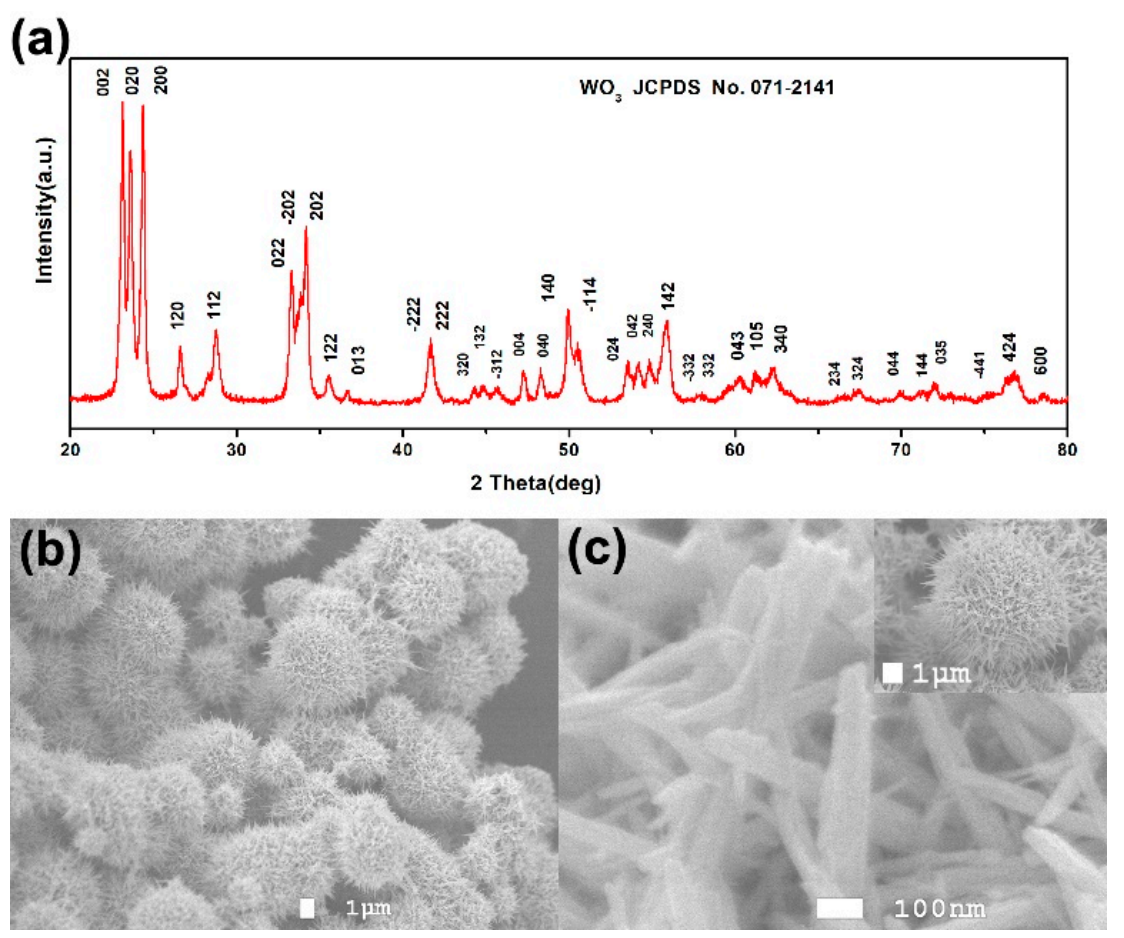

Figure 1. (a) X-ray diffraction (XRD) patterns ( $\mathrm{WO}_{3}$ JCPDS No.071-2141); (b,c) low to high magnification scanning-electron-microscopy (SEM) images of 3D urchinlike $\mathrm{WO}_{3}$ microsphere sample.

The individual and high magnification SEM images of the $\mathrm{WO}_{3}$ microstructure are shown in Figure 2c,d. The unique microstructure was self-assembled by nanorods with diameters of 70 to $100 \mathrm{~nm}$ forming surface roughness and a porous core with radially standing nanothorns, with an average length of 400 to $1000 \mathrm{~nm}$, and it showed an urchinlike hierarchical microstructure. Meanwhile, some nanothorns randomly overlapped, forming the connected and quasiconnected networks, and the surface of the nanothorns was rough and uneven. Unlike other $\mathrm{WO}_{3}$ materials, the sea urchin-shaped $\mathrm{WO}_{3}$ was composed of numerous $\mathrm{WO}_{3}$ nanorods. Even if more active materials were bonded to the current collector, this microstructure could provide a more effective working area to obtain better charge-storage capacity. Those structures together provided a significantly number of active sites for redox reactions, shortening electron transfer pathways, and reducing crystal-structure failure during the ion-insertion/-desertion processes.

To further confirm the chemical composition and valence states of the urchinlike $\mathrm{WO}_{3}$ sample, XPS measurements were conducted. The typical survey spectrum of the sample is shown in Figure 2a, which indicated the presence of W, C, and O elements; no other elements could be found. Figure $2 \mathrm{~b}$ shows the C1s spectrum, which could be fitted to two peaks located at 284.6 and $286.3 \mathrm{eV}$, caused by the vacuum oil contamination of the XPS equipment [14-16]. The high-resolution spectrum of the W4f core level of the urchinlike $\mathrm{WO}_{3}$ sample is shown in Figure 2d, which reveals two main peaks at 35.9 and $38.1 \mathrm{eV}$, with spin-energy separation of $2.2 \mathrm{eV}$ that can be assigned to the binding energy of $\mathrm{W}^{4} \mathrm{f}_{7 / 2}$ and $\mathrm{W}_{4} \mathrm{f}_{5 / 2}$, indicating the presence of $\mathrm{W}^{6+}$ in the sample [17]. Meanwhile, one peak located at $41.7 \mathrm{eV}$ could be assigned to binding energy of W5 $\mathrm{p}_{3 / 2}$, which also indicated the existence of $\mathrm{W}^{6}+$ states [18]. 
The spectrum of O1s showed one peak at $530.8 \mathrm{eV}$, as shown in Figure 2c, which could be assigned to the metal-oxygen bonds of the $\mathrm{WO}_{3}$ phase. These observations, together with the XRD results, confirmed that the sample was prepared.
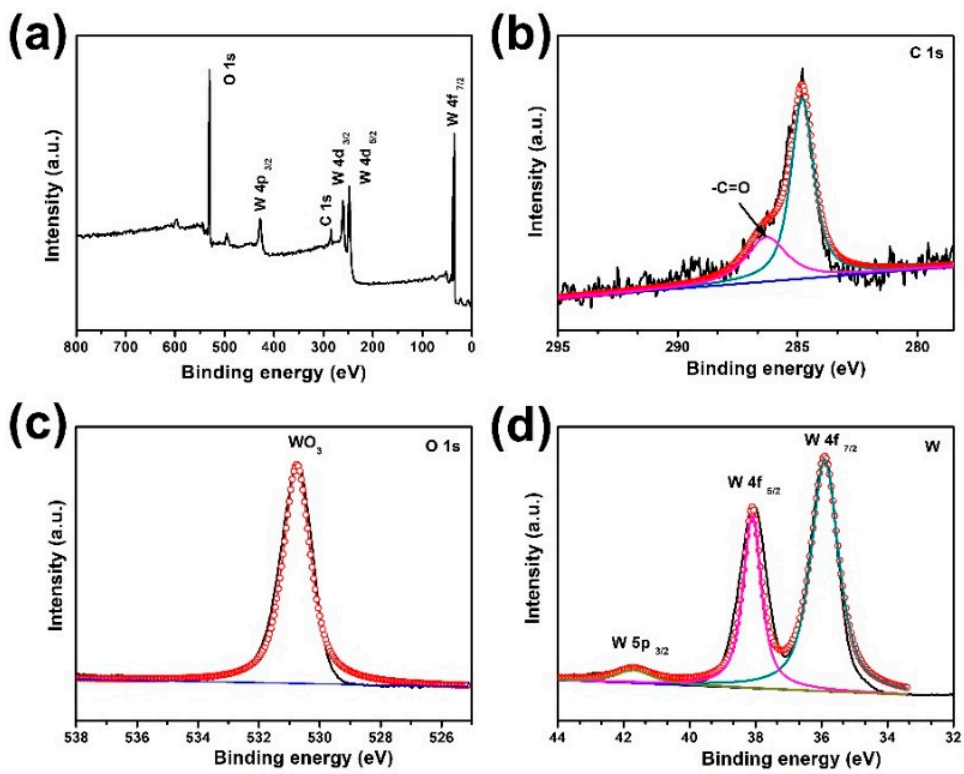

Figure 2. X-ray photoelectron spectroscopy (XPS) spectra of 3D urchinlike $\mathrm{WO}_{3}$ microsphere sample:

(a) survey XPS spectrum, core-level XPS spectra of (b) C 1s, (c) O1s, and (d) W elements.

To evaluate the electrochemical performance of the $\mathrm{WO}_{3}$ electrode, typical CV and GCD measurements were conducted in a three-electrode configuration with $2 \mathrm{M} \mathrm{H}_{2} \mathrm{SO}_{4}$ aqueous solution as electrolyte. Figure 3a shows the $\mathrm{CV}$ curves of the $\mathrm{WO}_{3}$ electrode collected from different scan rates, from 2 to $50 \mathrm{mV} \mathrm{s}^{-1}$. The profiles of the $\mathrm{CV}$ curves were obviously different from the typical rectangular shape of electrical double-layer capacitors, revealing the pseudocapacitive-capacitance characteristics of the $\mathrm{WO}_{3}$ electrode. The peak current and integral areas of the $\mathrm{WO}_{3}$ electrode were significantly increased with the increase of the scan rate, revealing fast charge-transfer and ion-insertion/-desertion properties. In the meantime, CV profiles at low scan rates could be maintained, and three pairs of redox peaks could be observed, revealing good reversibility. However, distortion CV profiles could be observed at high scan rates, and only two unobvious anodic peaks and two broad cathodic peaks could be observed, indicating the redox mechanism was dominant by the mass transfer [19]. Meanwhile, the position of anodic peaks cathodic peaks shifted separately to higher and lower potential with the increase of the scan rates, revealing the fast current response of the material. The properties of the $\mathrm{WO}_{3}$ pseudocapacitance can be explained by the following equation [20]:

$$
\mathrm{WO}_{3}+x \mathrm{H}^{+}+x e^{-} \leftrightarrow \mathrm{H}_{x} \mathrm{WO}_{3}
$$

Figure $3 b$ shows the GCD curves of the $\mathrm{WO}_{3}$ electrode at different current densities within a potential window of -0.35 to $0.1 \mathrm{~V}$. The GCD curves exhibited almost linear properties, with only some slight curvature changes in the charge curve and at about $-1.0 \mathrm{~V}$ in the discharge curve, corresponding to the anodic and cathodic peaks in the $\mathrm{CV}$ curves, indicating the Faradaic pseudocapacitive characteristic of the $\mathrm{WO}_{3}$ electrode. Meanwhile, the discharge curves showed relatively low $V_{\text {drop }}$, even at high current density, revealing the fast $I-V$ response property of the material [21]. The average equivalent-series resistance of the sample was calculated to only be $0.966 \Omega \mathrm{cm}^{-2}$ according to the $V_{\text {drop }}$ through all current densities by Equation (2) [17]:

$$
R_{E S R}=\frac{V_{d r o p}}{2 I}
$$


(a)

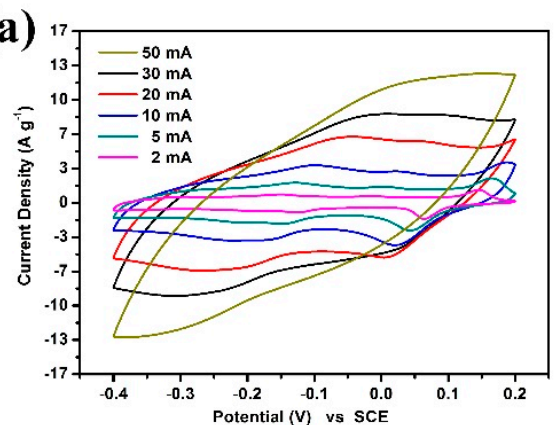

(c)

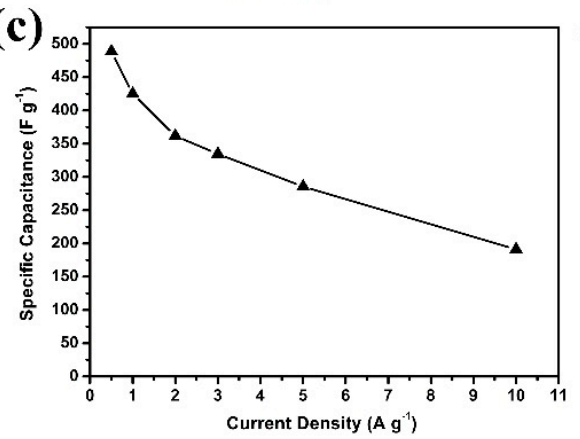

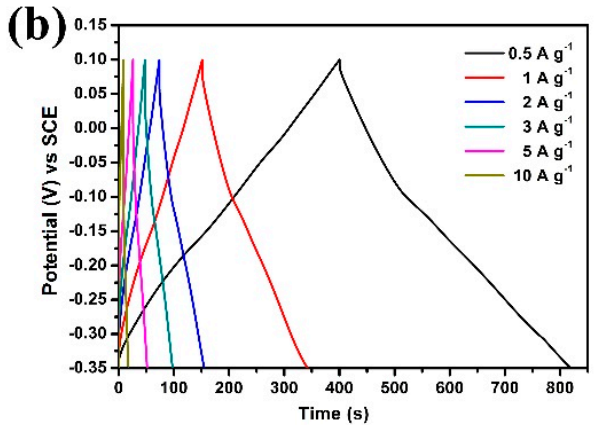

(d)

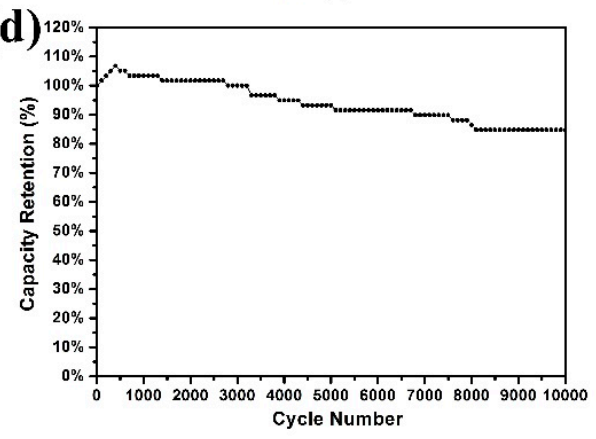

Figure 3. (a) Cycle voltammetry (CV) and (b) galvanostatic charge-discharge (GCD) curves, (c) specific capacitance, and (d) cycling performance of $3 \mathrm{D}$ urchinlike $\mathrm{WO}_{3}$ microsphere electrodes.

The charging and discharging curves exhibited almost symmetric property, accounting for good redox reversibility. With more linear and smoother charging and discharging curves, the $\mathrm{WO}_{3}$ electrode may be more suitable in high-energy-storage devices. The specific capacitance values could be calculated according to the discharge time by using the following equation [22]:

$$
C_{s}=\frac{I \Delta t}{m \Delta V}
$$

Where $C_{s}\left(\mathrm{~F} \mathrm{~g}^{-1}\right)$ is specific capacitance, $I(\mathrm{~A})$ is charge-discharge current, $\Delta t(\mathrm{~s})$ is discharging time, $\Delta V(\mathrm{~V})$ is voltage window, and $m(\mathrm{~g})$ is the mass of the active material within the electrode. The specific capacitances were calculated to be $488.78,425.11,361.78,334.67,285.56$, and $191.11 \mathrm{~F} \mathrm{~g}^{-1}$ at $0.5,1,2,3$, 5 , and $10 \mathrm{~A} \mathrm{~g} \mathrm{~g}^{-1}$ (Figure 3c), respectively. Moreover, with excellent capacitance, the 3D urchinlike $\mathrm{WO}_{3}$ electrode revealed excellent long-term cycling stability. As shown in Figure 3d, capacitance reached $106.78 \%$ of its initial value during the first 400 cycles caused by the activation of the electrode. In the rest of the cycling test, capacitance retention was maintained at nearly 100\% until 3000 cycles, when it was then slightly decreased to $84.75 \%$ of its initial value after the 10,000 cycle test, which showed better cycling performance than previously reported [23-25], indicating the excellent cycling stability and the practical-application potential of the 3D urchinlike $\mathrm{WO}_{3}$ electrode. Based on the above characteristics, urchinlike $\mathrm{WO}_{3}$ materials may be used as the base material of composite supercapacitor electrode materials to prepare electrode materials with excellent performance. This work is still in progress.

\section{Conclusions}

In summary, hierarchical $3 \mathrm{D}$ urchinlike $\mathrm{WO}_{3}$ microspheres were synthesized with the hydrothermal method. Benefiting from a unique microstructure consisting of $\mathrm{WO}_{3}$ nanorods with a porous core and a connected and quasiconnected nanothorn network shell, compared to previous reports about $\mathrm{WO}_{3}$ enumerated by Pragati A. Shinde et al. [26], the $\mathrm{WO}_{3}$ electrode exhibited a relatively high specific capacitance of $488.78 \mathrm{~F} \mathrm{~g}^{-1}$. Unlike other reports, the $\mathrm{WO}_{3}$ in this work was in powder form and could be combined with the substrate with better application value (including higher mass load, $10 \mathrm{mg} / \mathrm{cm}^{2}$ here) [27-31]. In addition, it had a low average $R_{\mathrm{ESR}}$ of $0.966 \Omega \mathrm{cm}^{-2}$ and excellent stability. 
These indicate that urchinlike $\mathrm{WO}_{3}$ electrodes would be promising electrodes for supercapacitor applications and may extend the potential application of transition metal oxide-based devices.

Author Contributions: Conceptualization, X.H., X.Y., H.S. and C.Z., experiments, J.W.; writing-original-draft preparation, D.H.; writing-review and editing, D.H. and J.W.

Funding: This work was financially supported by the Jilin Provincial Science and Technology Development Foundation (Grant No. 20180201011GX), the China Scholarship Council (CSC) State Scholarship Fund International Clean Energy Talent Project (Grant No. [2019]157), the National Key Technology R and D Program of China (Grant No. 2016YFB0401103), and the National Natural Science Foundation of China (Grant No. 51672103).

Conflicts of Interest: The authors declare no conflict of interest.

\section{References}

1. Kate, R.S.; Khalate, S.A.; Deokate, R.J. Overview of nanostructured metal oxides and pure nickel oxide (NiO) electrodes for supercapacitors: A review. J. Alloy. Compd. 2018, 734, 89-111. [CrossRef]

2. Zhang, G.; Liu, X.; Wang, Y.; Liu, C.; Xing, S. Achieving $\mathrm{MnO}_{2}$ nanosheets through surface redox reaction on nickel nanochains for catalysis and energy storage. Chemistry 2017, 23, 5557-5564. [CrossRef] [PubMed]

3. Lo, I.H.; Wang, J.Y.; Huang, K.Y.; Huang, J.H.; Kang, W.P. Synthesis of $\mathrm{Ni}(\mathrm{OH})_{2}$ nanoflakes on $\mathrm{ZnO}$ nanowires by pulse electrodeposition for high-performance supercapacitors. J. Power Sources 2016, 308, 29-36. [CrossRef]

4. Shao, Y.L.; El-Kady, M.F.; Sun, J.Y.; Li, Y.G.; Zhang, Q.H.; Zhu, M.F.; Wang, H.Z.; Dunn, B.; Kaner, R.B. Design and mechanisms of asymmetric supercapacitors. Chem. Rev. 2018, 118, 9233-9280. [CrossRef] [PubMed]

5. Dubal, D.P.; Ayyad, O.; Ruiz, V.; Gomez-Romero, P. Hybrid energy storage: The merging of battery and supercapacitor chemistries. Chem. Soc. Rev. 2015, 44, 1777-1790. [CrossRef]

6. Gao, L.; Zhang, L.L.; Jia, S.Y.; Liu, X.C.; Wang, Y.H.; Xing, S.X. Facile route to achieve hierarchical hollow $\mathrm{MnO}_{2}$ nanostructures. Electrochimica Acta 2016, 203, 59-65. [CrossRef]

7. Xiao, T.; Li, J.; Zhuang, X.Y.; Zhang, W.; Wang, S.L.; Chen, X.L.; Xiang, P.; Jiang, L.H.; Tan, X.Y. Wide potential window and high specific capacitance triggered via rough $\mathrm{NiCo}_{2} \mathrm{~S}_{4}$ nanorod arrays with open top for symmetric supercapacitors. Electrochimica Acta 2018, 269, 397-404. [CrossRef]

8. Zhang, P.; Guan, B.Y.; Yu, L.; Lou, X.W.D. Formation of Double-Shelled Zinc-Cobalt Sulfide Dodecahedral Cages from Bimetallic Zeolitic Imidazolate Frameworks for Hybrid Supercapacitors. Angew. Chem. Int. Ed. Engl. 2017, 56, 7141-7145. [CrossRef]

9. Yao, Y.; Yin, M.; Yan, J.; Liu, S.F. P-type sub-tungsten-oxide based urchin-like nanostructure for superior room temperature alcohol sensor. Appl. Surf. Sci. 2018, 441, 277-284. [CrossRef]

10. Li, X.; Sun, L.; Hu, M.; Huang, R.; Huang, C. Hydrothermal Synthesis of Urchin-like WVO Nanostructures with Excellent Catalytic Performance. Inorg. Chem. 2018, 57, 14758-14763. [CrossRef]

11. Xu, J.; Ding, T.T.; Wang, J.; Zhang, J.; Wang, S.; Chen, C.Q.; Fang, Y.Y.; Wu, Z.H.; Huo, K.F.; Dai, J.N. Tungsten oxide nanofibers self-assembled mesoscopic microspheres as high-performance electrodes for supercapacitor. Electrochimica Acta 2015, 174, 728-734. [CrossRef]

12. Yoon, S.; Kang, E.; Kim, J.K.; Lee, C.W.; Lee, J. Development of high-performance supercapacitor electrodes using novel ordered mesoporous tungsten oxide materials with high electrical conductivity. Chem. Commun. 2011, 47, 1021-1023. [CrossRef] [PubMed]

13. Rodríguez-Moreno, J.; Navarrete-Astorga, E.; Dalchiele, E.A.; Schrebler, R.; Ramos-Barrado, J.R.; Martín, F. Vertically aligned ZnO@ CuS@ PEDOT core@ shell nanorod arrays decorated with $\mathrm{MnO}_{2}$ nanoparticles for a high-performance and semi-transparent supercapacitor electrode. Chem. Commun. 2014, 50, 5652-5655. [CrossRef] [PubMed]

14. Shinde, S.K.; Dubal, D.P.; Ghodake, G.S.; Kim, D.Y.; Fulari, V.J. Nanoflower-like $\mathrm{CuO} / \mathrm{Cu}(\mathrm{OH})_{2}$ hybrid thin films: Synthesis and electrochemical supercapacitive properties. J. Electroanal. Chem. 2014, 732, 80-85. [CrossRef]

15. Dubal, D.P.; Gund, G.S.; Holze, R.; Jadhav, H.S.; Lokhande, C.D.; Park, C.J. Surfactant-assisted morphological tuning of hierarchical $\mathrm{CuO}$ thin films for electrochemical supercapacitors. Dalton Trans. 2013, 42, 6459-6467. [CrossRef]

16. Chen, J.; Xu, J.; Zhou, S.; Zhao, N.; Wong, C.P. Facile and scalable fabrication of three-dimensional $\mathrm{Cu}(\mathrm{OH})_{2}$ nanoporous nanorods for solid-state supercapacitors. J. Mater. Chem. A 2015, 3, 17385-17391. [CrossRef] 
17. Poongodi, S.; Kumar, P.S.; Mangalaraj, D.; Ponpandian, N.; Meena, P.; Masuda, Y.; Lee, C. Electrodeposition of $\mathrm{WO}_{3}$ nanostructured thin films for electrochromic and $\mathrm{H}_{2} \mathrm{~S}$ gas sensor applications. J. Alloy. Compd. 2017, 719, 71-81. [CrossRef]

18. Sarma, D.D.; Rao, C.N.R. XPES studies of oxides of second-and third-row transition metals including rare earths. J. Electron Spectrosc. Relat. Phenom. 1980, 20, 25-45. [CrossRef]

19. Jiang, Y.; Leng, X.J.; Jia, Z.L.; Chen, H.X.; Suo, H.; Zhao, C. In situ growth of NiO nanostructures directly on nickel foam and its electrochemical property. J. Mater. Sci. Mater. Electron. 2015, 26, 2995-3000. [CrossRef]

20. Gao, L.N.; Wang, X.F.; Xie, Z.; Song, W.F.; Wang, L.J.; Wu, X.; Qu, F.Y.; Chen, D.; Shen, G.Z. High-performance energy-storage devices based on $\mathrm{WO}_{3}$ nanowire arrays/carbon cloth integrated electrodes. J. Mater. Chem. A 2013, 1, 7167-7173. [CrossRef]

21. Salunkhe, R.R.; Tang, J.; Kamachi, Y.; Nakato, T.; Kim, J.H.; Yamauchi, Y. Asymmetric supercapacitors using 3D nanoporous carbon and cobalt oxide electrodes synthesized from a single metal-Organic framework. Acs Nano 2015, 9, 6288-6296. [CrossRef]

22. Zhong, C.; Deng, Y.; Hu, W.; Qiao, J.; Zhang, L.; Zhang, J. A review of electrolyte materials and compositions for electrochemical supercapacitors. Chem. Soc. Rev. 2015, 44, 7484-7539. [CrossRef] [PubMed]

23. Yao, S.Y.; Qu, F.Y.; Wang, G.; Wu, X. Facile hydrothermal synthesis of $\mathrm{WO}_{3}$ nanorods for photocatalysts and supercapacitors. J. Alloy. Compd. 2017, 724, 695-702. [CrossRef]

24. Shinde, P.A.; Lokhande, A.C.; Chodankar, N.R.; Patil, A.M.; Kim, J.H.; Lokhande, C.D. Temperature dependent surface morphological modifications of hexagonal $\mathrm{WO}_{3}$ thin films for high performance supercapacitor application. Electrochimica Acta 2017, 224, 397-404. [CrossRef]

25. Zheng, F.; Gong, H.Q.; Li, Z.; Yang, W.G.; Xu, J.H.; Hu, P.F.; Li, Y.; Gong, Y.; Zhen, Q. Tertiary structure of cactus-like $\mathrm{WO}_{3}$ spheres self-assembled on $\mathrm{Cu}$ foil for supercapacitive electrode materials. J. Alloy. Compd. 2017, 712, 345-354. [CrossRef]

26. Shinde, P.A.; Lokhande, A.C.; Patil, A.M.; Lokhande, C.D. Facile synthesis of self-assembled $\mathrm{WO}_{3}$ nanorods for high-performance electrochemical capacitor. J. Alloy. Comp. 2019, 770, 1130-1137. [CrossRef]

27. Shinde, N.M.; Jagadale, A.D.; Kumbhar, V.S.; Rana, T.R.; Kim, J.H.; Lokhande, C.D. Wet chemical synthesis of $\mathrm{WO}_{3}$ thin films for supercapacitor application. Korean J. Chem. Eng. 2015, 32, 974. [CrossRef]

28. Zheng, F.; Song, S.; Lu, F.; Li, R.; Bu, N.; Liu, J.; Li, Y.; Hud, P.; Zhen, Q. Hydrothermal preparation, growth mechanism and supercapacitive properties of $\mathrm{WO}_{3}$ nanorod arrays grown directly on a $\mathrm{Cu}$ substrate. CrystEngComm 2016, 18, 3891. [CrossRef]

29. Qiu, M.; Sun, P.; Shen, L.; Wang, K.; Song, S.; Yu, X.; Tan, S.; Zhao, C.; Mai, W. $\mathrm{WO}_{3}$ nanoflowers with excellent pseudo-capacitive performance and the capacitance contribution analysis. J. Mater. Chem. A 2016, 4, 7266. [CrossRef]

30. Zhu, M.; Meng, W.; Huang, Y.; Huang, Y.; Zhi, C. Proton-insertion-enhanced pseudocapacitance based on the assembly structure of tungsten oxide. ACS Appl. Mater. Interfaces 2014, 6, 18901-18910. [CrossRef]

31. Chang, K.H.; Hu, C.C.; Huang, C.M.; Liu, Y.L.; Chang, C.I. Microwave-assisted hydrothermal synthesis of crystalline $\mathrm{WO}_{3}-\mathrm{WO}_{3} \cdot 0.5 \mathrm{H}_{2} \mathrm{O}$ mixtures for pseudocapacitors of the asymmetric type. J. Power Sources 2011, 196, 2387. [CrossRef]

(C) 2019 by the authors. Licensee MDPI, Basel, Switzerland. This article is an open access article distributed under the terms and conditions of the Creative Commons Attribution (CC BY) license (http://creativecommons.org/licenses/by/4.0/). 